\title{
Spatial-temporal Variation of climate comfort in Qinhuangdao in the past 53 years
}

\author{
Jing Xu Xianmei Lu Zhigang Liu Jinmei Song \\ Qinhuangdao Meteorological office \\ Qinhuangdao 066000, China \\ qhdxj66@163.com \\ 53 年来秦皇岛气候舒适度时空变化分析 \\ 徐静 卢宪梅 刘志刚 宋金妹 \\ 秦皇岛市气象局 \\ 河北 秦皇岛 066000, 中国 \\ qhdxj66@163.com
}

\begin{abstract}
Based on meteorological data in the past 53 years (1966-2018), this paper analyzes the climate comfort changes in Qinhuangdao by using the method of climate comfort evaluation and trend analysis. The results show that the climate comfort changes in the northern mountainous area of Qinhuangdao, the central plain and the southeastern coastal areas are consistent, and there are spatial differences. In general, Qinhuangdao's climate comfort is mainly comfortable to cool, the comfort and relative comfort levels of each region account for $47 \%$ to $49 \%$, and the cold discomfort level accounts for $34 \%$ to $37 \%$, the hot and hotter discomfort levels are rare. In the past 53 years, the climate comfort in summer and winter shows a warming trend, and the warming range in winter was larger than that in summer. In the past 53 years, the number of hot uncomfortable days has increased sharply since the 1990s, and the number of cold uncomfortable days has decreased year by year. The number of hot uncomfortable days increases with the decrease of altitude and latitude of the station in space, while the number of cold uncomfortable days is the opposite. The climate is comfortable or relatively comfortable from May to October. The whole area of Qinhuangdao is suitable for tourism and recuperation from May to October. There is no intense hot in July and August. The "slightly hot" weather provides favorable weather conditions for people to swim in the sea, the relative cold climate in March, April and November is a good time for outdoor mountain climbing, the climate is cold and uncomfortable from December to February, not suitable for mass tourism, but suitable for ice and snow tourism activities. Therefore, it can be considered that Qinhuangdao is suitable for tourism all seasons. This provides a basis for tourism development and planning in Qinhuangdao and for studying the impact of climate change on tourism, and provides life and travel weather service guidance for the Kangyang group that came to "Qinhuangshanhai, Kangyangfudi".
\end{abstract}

Key words: Climate comfort degree; Spatial and temporal variation; Uncomfortable days; Qinhuangdao; KangYang
摘要一利用 1966一 2018 年气象资料, 采用气候舒适度 评价及趋势分析方法, 对秦皇岛地区近 $53 \mathrm{a}$ 气候舒适度 变化进行分析。结果表明: 秦皇岛北部山区、中部平原和 东南沿海三个区域的气候舒适度变化趋势一致, 存在空间 差异性。整体上, 秦皇岛气候舒适度以舒适至冷凉特征为 主, 各区域舒适和较舒适等级占 $47 \%-49 \%$, 冷不舒适等级 占 $34 \%$ - $37 \%$, 炎热及更热不舒适等级极少。夏季、冬季气 候舒适度均呈增暖趋势, 冬季增暖幅度大于夏季。热不舒 适日数自 90 年代开始激增且持续偏多, 寒冷不舒适日数 呈逐年代减少态势; 在空间上, 热不舒适日数随着测站高 程和纬度的降低而增多, 寒冷不舒适日数与之相反。

关键词一气候舒适度, 时空变化, 不舒适日数

$$
\text { I. 引言 }
$$

气候舒适度是评价健康人群在无需借助任何防 寒、避暑装备和设施情况下对气候因子感觉适宜程度 的气象指标。早在 1966 年, W.H.Terjung 提出了气候 舒适性指数的概念 ${ }^{[1]}$, J.E.Oliver 进一步探讨了气象要 素对人体舒适感觉的影响[2]。国内相关研究最初是引 入国外方法, 之后吴兄、郑衡宇、陈桂标等学者进行

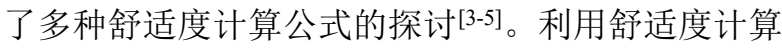
公式, 孙广禄 ${ }^{[6]}$ 指出京津冀地区舒适度与高程和纬度 变化存在负相关; 肖晶晶 ${ }^{[7]}$ 研究表明浙江省沿海和内 陆、浙南和浙北气候适宜度各不相同; 李树岩 ${ }^{[8]}$ 分析 了河南省气候指数, 得出春、秋季舒适度的年际变化 同温度呈显著正相关，夏季呈显著负相关；贾海源 ${ }^{[9]}$ 研究指出, 甘肃全省表现为冷到舒适的平均舒适度水 
平, 气候变化使甘肃的舒适日数增加; 马丽君 ${ }^{[10]}$ 研究 指出, 随着全球升温, 北京市旅游气候舒适度发生了 较大的变化; 房小怡 ${ }^{[11]}$ 对北京城郊的气候舒适度进行 了对比分析, 结果表明北京城郊气候舒适度存在明显 的年际变化和空间变化的差异性; 金琪 ${ }^{[12]}$ 对武汉城市 圈舒适度研究表明, 9 个城市舒适度指数均呈一致的 增加趋势; 另外, 李正泉、王秀兰 ${ }^{[13-14]}$ 研究了杭州市 舒适度变化及其影响, 吴世安、张立杰、刘金丽和王 繁强 ${ }^{15-18]}$ 分别对信阳、深圳、日照和珠海等城市进行 了舒适度分析, 赵子健分析了南京市热不舒适状况 ${ }^{[19]}$ 。 上述研究表明, 不同地区气候舒适度状况和变化各有 不同, 进行本地气候舒适度研究以满足日益提高的气 象服务需求很有必要。

秦皇岛是著名旅游避暑胜地, 目前, 第一个国家 级生命健康产业创新示范区已经落户秦皇岛北戴河 区, 示范区将建成世界一流滨海康养旅游目的地。在 此背景之下, 秦皇岛气候舒适度分析成为气候变化的 研究重点。秦皇岛境内北部为海拔较高的山区, 中部 主要为丘陵和平原区, 东南部为近海岸线的沿海区, 三个区域气候尤其是气温具有一定的差异。本文利用 秦皇岛气象资料, 定量分析三个区域近 $53 \mathrm{a}$ 来气候舒 适度变化趋势及冷、热不舒适日数, 旨在为来到 “秦 皇山海、康养福地” 的康养群体提供生活和出游气象 服务指导, 为秦皇岛市旅游开发与规划及为研究气候 变化对旅游业的影响提供依据。

\section{II. 资料与方法}

本文所用资料为 1966-2018 年逐日气温、相对 湿度、风等常规观测资料, 来源于秦皇岛市气象局。 按照地理位置、海拔高度和气候条件, 将秦皇岛地区 划分为北部山区、中部平原和东南沿海三个区域, 分 别用青龙、抚宁、昌黎三个气象观测站作为代表站进 行气候舒适度分析, 各站站点位置、纬度和海拔高度 见图 1。在 1966-2018 年间, 三个观测站均进行过 迁站, 由于迁移距离较近, 通过对比观测数据分析, 迁站对气象要素略有影响, 在本文气候舒适度的分析 中其影响可以忽略不计。

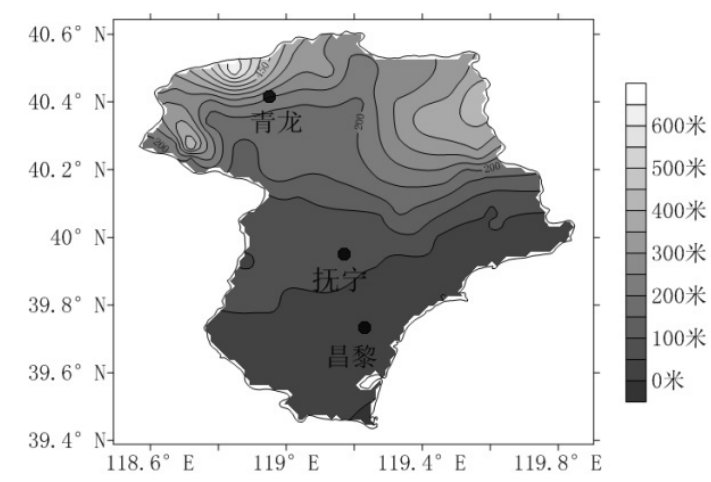

图 1 青龙、抚宁、昌黎气象观测站站点分布图

本文选用李源 ${ }^{[20]}$ 舒适度指数计算方法进行分析。 考虑到李源的研究区域武汉市与本研究区域的地理 及气候差异, 根据医学科学试验结果 “人体冷耐受的 下限温度为 $11{ }^{\circ} \mathrm{C}$ 和热耐受的上限温度为 $32{ }^{\circ} \mathrm{C}$ ”[21], 对公式中最高气温的阈值进行了调整, 以更加适合本 研究, 公式如下:

$K=\left\{\begin{array}{lc}\frac{9.0}{T_{\max }-T_{\min }}+\frac{R H-50.0}{15.0}-\frac{V-2.5}{3.0} \quad T_{\max } \geq 32 \\ T+\frac{R H-50.0}{15.0}-\frac{V-2.5}{3.0} \quad 11 \leq T_{\max }<32 \\ T-\frac{R H-50.0}{15.0}-\frac{V-2.5}{3.0} \quad T_{\max }<11\end{array}\right.$

式 (1) 中: $\mathrm{K}$ 为气候舒适度指数, $\mathrm{T}$ 为平均气温 $\left({ }^{\circ} \mathrm{C}\right), \mathrm{T}_{\max }$ 为最高气温 $\left({ }^{\circ} \mathrm{C}\right), \mathrm{T}_{\min }$ 为最低气温 $\left({ }^{\circ} \mathrm{C}\right)$, $\mathrm{RH}$ 为平均相对湿度 $(\%), \mathrm{V}$ 为平均风速 $(\mathrm{m} \cdot \mathrm{s}-$ 1)。

将气候舒适度划分成 11 个等级, 分级及对应的 $K$ 值范围、热感觉感受状态见表 1 。

表 1 气候舒适度等级划分标准

\begin{tabular}{ccl}
\hline 等级 & 舒适度指数范围 & \multicolumn{1}{c}{ 热感觉感受 } \\
\hline 5 & $K \geqslant 41.5$ & 热感觉定为极端热, 极不舒适 \\
4 & $37.5 \leqslant K<41.5$ & 热感觉定为酷热, 很不舒适 \\
3 & $34.5 \leqslant K<37.5$ & 热感觉定为炎热, 不舒适 \\
2 & $30.0 \leqslant K<34.5$ & 热感觉定为热, 较不舒适 \\
1 & $27.0 \leqslant K<30.0$ & 热感觉定为微热, 较舒适 \\
0 & $21.0 \leqslant K<27.0$ & 热感觉定为温和, 舒适 \\
-1 & $13.0 \leqslant K<21.0$ & 热感觉定为凉, 较舒适 \\
-2 & $5.0 \leqslant K<13.0$ & 热感觉定为微冷, 较不舒适 \\
-3 & $1.1 \leqslant K<5.0$ & 热感觉定为冷, 不舒适 \\
-4 & $-5.0 \leqslant K<1.1$ & 热感觉定为很冷, 很不舒适 \\
-5 & $K<-5.0$ & 热感觉定为寒冷, 极不舒适 \\
\hline
\end{tabular}

III. 结果分析

按照式 (1) 和表 1 , 统计近 53 a 秦皇岛三个区 
域气候舒适度各级别出现日数, 结果见表 2 。由表 2 可见, 近 $53 \mathrm{a}$, 秦皇岛气候舒适度主要集中在 “-5” 至 “ 1 ” 七个级别。“- 1 ” 至 “ 1 ” 级舒适和较舒适总 日数三个区域相差不多, 占总数的 $47 \%-49 \%$; “-3” 至 “ -5 ” 级冷不舒适日数占 $34 \%-37 \%$ 。其中, 寒冷 极不舒适的 “ -5 ” 级北部山区最多, 是中部平原的 1.5 倍、东南沿海的 2.2 倍, 这与高程高度和纬度成 反比, 即高程越高、纬度越高的地区气候舒适度越趋 向寒冷, 该结果与孙广禄 ${ }^{[6]}$ 等的研究结论 “京津冀地 区人体舒适度与高程、纬度变化均存在显著负相关, 空间分型的主导因素为高程、纬度的变化” 相一致。 各区域 “ 2 ” 级以上的日数极少, 气候舒适度总体呈 现舒适至冷凉的特征。

表 2 1966-2018 年秦皇岛各区域气候舒适度 各级别日数分布比例

\begin{tabular}{cccc}
\hline 等级 & 北部山区 & 中部平原 & 东南沿海 \\
\hline-5 & 15 & 10 & 7 \\
-4 & 14 & 17 & 18 \\
-3 & 8 & 9 & 9 \\
-2 & 15 & 14 & 15 \\
-1 & 16 & 16 & 16 \\
0 & 21 & 20 & 20 \\
1 & 10 & 12 & 13 \\
2 & 1 & 2 & 2 \\
3 & 0 & 0 & 0 \\
4 & 0 & 0 & 0 \\
5 & 0 & 0 & 0 \\
\hline
\end{tabular}

近 $53 \mathrm{a}$ 秦皇岛地区三个代表区域气候舒适度月 平均状况 (表 3) 较为相近。5-10 月各区域气候舒 适度主要在 “ -1 ” 至 “ 1 ” 级之间, 是气候舒适和较 舒适的时间段, 北部山区舒适期少一个月； 7、8 两 个月以 “ 1 ” 级为主, 无酷暑状态; 3 月、4 月和 11 月在 “- 3 ” 至 “- 2 ” 级之间, 气候微冷或冷不舒适, 此时秦皇岛地区降水偏少, 日照充足 ${ }^{[22]}$, 采取适当的 保暖措施后也比较舒适, 11 月中部平原和东南沿海 舒适度没有体现 “-2” 级, 表明这两个区域秋季舒适 度指数下降梯度大, 变冷速度快; 12 月到次年 2 月 在 “-5” 至 “- 4 ” 级之间, 气候寒冷不舒适, “- 5 ” 级持续时间为北部山区两个月、中部平原一个月、东 南沿海未达 “-5”级。
表 3 1966-2018 年秦皇岛地区月平均气候舒适度 等级

\begin{tabular}{cccc}
\hline 月份 & 北部山区 & 中部平原 & 东南沿海 \\
\hline 1 & -5 & -5 & -4 \\
2 & -4 & -4 & -4 \\
3 & -3 & -3 & -3 \\
4 & -2 & -2 & -2 \\
5 & -1 & -1 & -1 \\
6 & 0 & 0 & 0 \\
7 & 1 & 1 & 1 \\
8 & 0 & 1 & 1 \\
9 & -1 & 0 & 0 \\
10 & -2 & -1 & -1 \\
11 & -3 & -3 & -3 \\
12 & -5 & -4 & -4 \\
\hline
\end{tabular}

由表 3 可见, 7 月和 8 月舒适度指数多为“ 1 ”级, 与其相比 6 月偏低一个等级，7、8 两个月的平均状 况更能反映夏季天气炎热对人们舒适程度的影响, 因 此, 本文以 $7 、 8$ 两个月舒适度指数平均值代表夏季 进行夏季舒适度变化特征分析。

由夏季气候舒适度指数累积距平曲线（图 2) 可 见, 各区域的变化趋势一致, 其变化可以分为三个阶 段。 20 世纪 90 年代之前曲线趋势稳定下降, 舒适度 指数处于持续偏低阶段; 进入九十年代之后, 曲线波 动性大, 说明此阶段气候舒适度变化不稳定; 进入 21 世纪曲线总体趋势变化小, 该阶段气候舒适度 变化幅度不大, 但是近 $3 \mathrm{a}$ 曲线跃升, 表明夏季持 续变热。

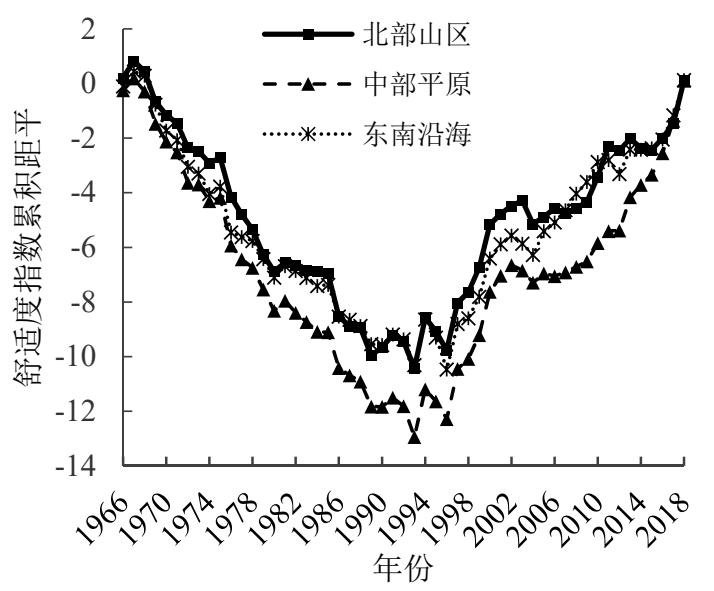

图 2 1966-2018 年秦皇岛地区 夏季平均气候舒适度指数累积距平

图 3 是近 $53 \mathrm{a}$ 北部山区夏季平均气温和各区域夏 季平均舒适度指数变化曲线, 分析由累积距平曲线判 断的三个变化持续阶段可见，20 世纪九十年代之前 
气温呈平稳偏低状态, 此时舒适度指数普遍偏低, 是 近 $53 \mathrm{a}$ 来夏季相对较为凉爽的时期; 进入九十年代之 后, 气温和舒适度指数的年际震荡明显增加, 凉、热 夏季间隔出现; 到了 21 世纪初, 气温处于持续偏高 阶段, 相应的各地舒适度指数呈小幅震荡偏高状态, 近 $3 \mathrm{a}$ 各区域舒适度指数跃升, 夏季增热显著。气温 和舒适度指数变化曲线均呈上升趋势, 通过了 0.05 的显著性检验, 气温增长率为 $0.28 / 10 \mathrm{a}$, 各区域舒适 度指数增长率在 $0.22-0.29 / 10 \mathrm{a}$ 之间, 二者变暖程度 大致相同, 呈显著正相关, 说明气温是影响舒适度指 数的主要因素。气温值低于舒适度指数值, 是由于夏 季平均相对湿度为 $80 \%$, 表明在气温较高时, 相对湿 度偏高会增大人体不舒适的感觉程度, 相对湿度是影 响夏季气候舒适度的重要因素。

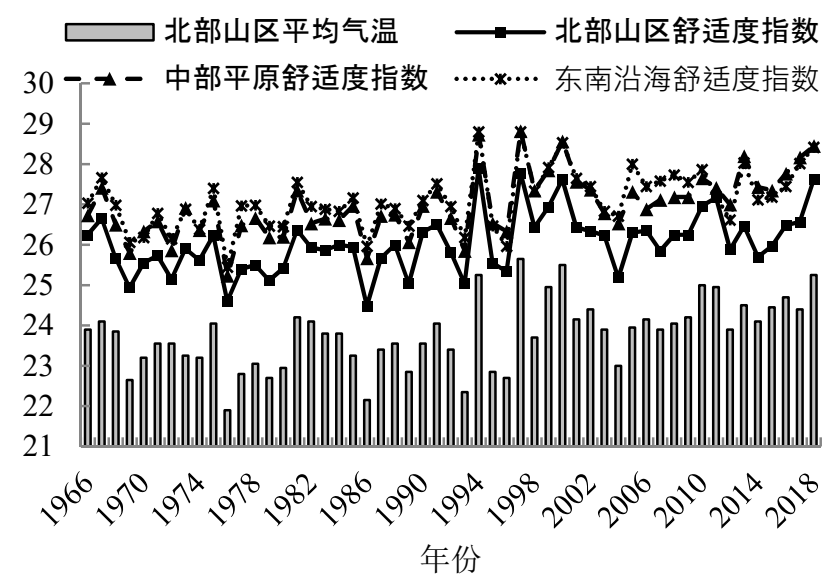

图 3 1966－2018 年秦皇岛地区夏季平均气候舒 适度指数和平均气温年变化

图4是近53 a北部山区冬季平均气温和各区域冬 季平均舒适度指数变化曲线, 同样可由冬季舒适度指 数累积距平曲线 (图略) 判断出三个变化持续阶段。 1966-1987年间, 气温和舒适度指数整体偏低, 是近 53 a来冬季持续寒冷的时期; 1988-1998年间, 气温 明显升高变化稳定, 舒适度指数也呈偏高态势, 是冬 季较为温暖的年代; 1999-2018年间, 气温呈高低震 荡变化, 舒适度指数波动性也明显增大, 各区域舒适 度以准 3 年的周期在 “- 4 ” 至 “ -5 ” 等级间进行相对而 言的冷暖年震荡。气温和舒适度指数变化曲线均呈上 升趋势, 通过了 0.05 的显著性检验, 气温增长率为 $0.52 / 10 \mathrm{a}$, 各区域舒适度指数增长率在 $0.37-0.72 / 10 \mathrm{a}$ 之间, 上升幅度均大于夏季, 表明冬季增暖趋势大于 夏季。与夏季不同的是, 气温值与舒适度指数值基本 吻合, 经分析发现, 冬季平均相对湿度为 $51 \%$, 由公 式 (1) 可见, 对舒适度指数影响不大, 因此, 气温 是影响冬季气候舒适度的最主要因素。
秦皇岛市是著名的旅游避暑城市, 热不舒适日数 的多少受到大家关注。表4给出了近 $53 \mathrm{a}$ 各区域热不舒 适日数的年代际变化统计结果。显示 20 世纪 90 年代前 热不舒适日数平均为 $3.5 \mathrm{~d} /$ 年，90年代开始激增且持 续偏多, 平均为 $6.9 \mathrm{~d} /$ 年, 变化趋势为显著增多态势, 该结果与张楠 ${ }^{[23]}$ 等华北地区夏季气温变化趋势结论 基本一致, 可见热不舒适日数的增多与气候变暖 ${ }^{[24]}$ 的气候背景密切相关。北部山区、中部平原和东南沿 海热不舒适日数之比为 1.0:1.9:2.1, 热不舒适日数随 着测站高程和纬度的降低而增多。

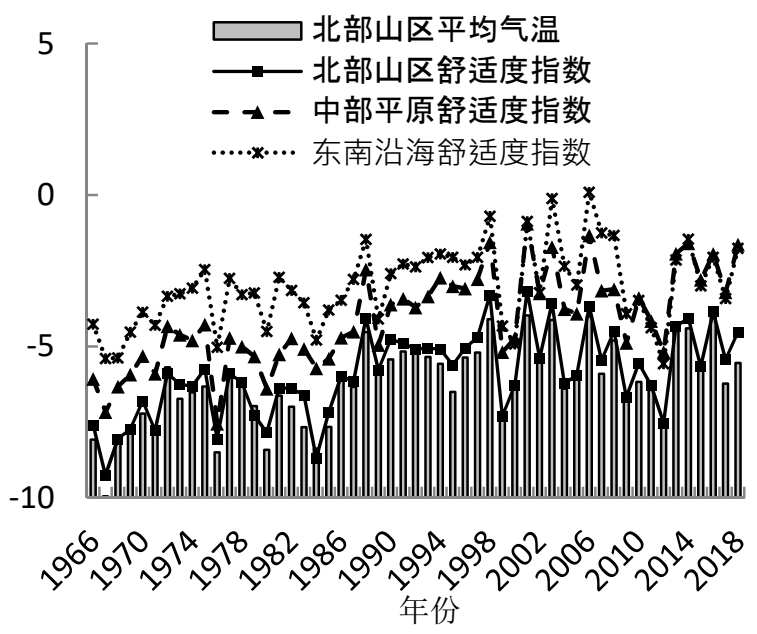

图 4 1966-2018 年秦皇岛地区冬季平均气候舒 适度指数和平均气温年变化

表 4 年代际热不舒适日数统计

\begin{tabular}{cccc}
\hline 年份 & 北部山区 & 中部平原 & 东南沿海 \\
\hline $1966-1970$ & $2.4 \mathrm{~d}$ & $3.8 \mathrm{~d}$ & $5.2 \mathrm{~d}$ \\
$1971-1980$ & $1.7 \mathrm{~d}$ & $3.5 \mathrm{~d}$ & $4.3 \mathrm{~d}$ \\
$1981-1990$ & $2.6 \mathrm{~d}$ & $3.8 \mathrm{~d}$ & $4.6 \mathrm{~d}$ \\
$1991-2000$ & $5.2 \mathrm{~d}$ & $9.4 \mathrm{~d}$ & $10.1 \mathrm{~d}$ \\
$2001-2010$ & $3.3 \mathrm{~d}$ & $7.0 \mathrm{~d}$ & $8.0 \mathrm{~d}$ \\
$2011-2018$ & $4.9 \mathrm{~d}$ & $11.6 \mathrm{~d}$ & $9.9 \mathrm{~d}$ \\
\hline
\end{tabular}

寒冷极不舒适日数的多少直接影响人们对冷暖 冬的直观感觉。根据气候舒适度达到 “- 5 ” 级的寒冷 极不舒适日数年代际统计结果（表5）可见：60年代 中后期寒冷日数最多, 其后基本呈逐年代减少态势, 这与王海军 ${ }^{[25]}$ 等对华北冬季 20 世纪 70 年代之前为持 续冷冬期、80年代中期之后为持续暖冬期、其间相对 正常的研究结论相一致。整体上看, 随着气候变暖, 近 53 a 寒冷极不舒适日数减少趋势明显, 提高了冬季 舒适程度。各区域的空间差异见2.1节中 “各级别分 布特征”部分。 
表 5 年代际寒冷极不舒适日数统计

\begin{tabular}{cccc}
\hline 年份 & 北部山区 & 中部平原 & 东南沿海 \\
\hline $1966-1970$ & $72.8 d$ & $56.2 \mathrm{~d}$ & $43.6 \mathrm{~d}$ \\
$1971-1980$ & $61.7 \mathrm{~d}$ & $48.4 \mathrm{~d}$ & $29.6 \mathrm{~d}$ \\
$1981-1990$ & $58.6 \mathrm{~d}$ & $43.6 \mathrm{~d}$ & $29.3 \mathrm{~d}$ \\
$1991-2000$ & $48.6 \mathrm{~d}$ & $26.3 \mathrm{~d}$ & $17.5 \mathrm{~d}$ \\
$2001-2010$ & $50.1 \mathrm{~d}$ & $25.8 \mathrm{~d}$ & $18.4 \mathrm{~d}$ \\
$2011-2018$ & $49.1 \mathrm{~d}$ & $24.8 \mathrm{~d}$ & $18.0 \mathrm{~d}$ \\
\hline
\end{tabular}

IV. 结论与讨论

（1）秦皇岛地区气候舒适度整体呈现舒适至冷 凉特征, 无 “炎热” 及以上级别, 各区域舒适和较舒 适等级占 $47 \%-49 \%$, 冷不舒适等级占 $34 \%-37 \%$ 。 5-10月气候舒适或较舒适, 7、8两个月无酷暑状态, 是名副其实的避暑圣地, “微热” 的天气为人们提供 畅游大海的有利气象条件; 3 月、4月和 11 月舒适度增 加或降低幅度大, 采取适当的保暖措施后也比较舒适; 12月一2月寒冷不舒适。

(2) 气温是影响气候舒适度的主要因素。秦皇 岛地区夏季空气湿度偏大, 增加了热不舒适感觉程度; 冬季空气湿度适中, 气候舒适度主要受气温影响。对 比分析北部山区、中部平原和东南沿海发现, 近 $53 \mathrm{a}$, 夏季、冬季平均舒适度指数均呈上升趋势, 冬季上升 趋势大于夏季; 各区域热不舒适日数自 90 年代开始激 增且持续偏多, 寒冷不舒适日数基本呈逐年代减少态 势, 提高了冬季舒适程度, 这些变化都与气候变暖的 气候背景密切相关; 三个区域热不舒适日数随着测站 高程和纬度的降低而增多, 寒冷不舒适日数与之相反。

（3）一年中，5一-10月秦皇岛全域均为旅游、疗 养适宜期; 3 月、 4 月和 11 月份气候偏冷凉, 此时秦皇 岛地区降水偏少, 日照充足, 是户外登山的大好时机, 北部山区和中部平原峰峦叠嶂、峡谷纵横, 是户外徒 步和登山的理想之地; 1 月、2月和12月份, 秦皇岛地 区尤其是北部山区气候寒冷, 不适宜大众旅游疗养, 但却是开展冰雪旅游必须的气象条件, 在做好保暖工 作的前提下, 户外冰雪活动爱好者仍可进行旅游活动。 因此, 可以认为秦皇岛全域、全季皆适宜旅游。在目 前气象服务基础上, 可以深入开展具体景区景点、特 殊时段等针对性强的舒适度气象服务, 从而优化旅游 路线、丰富旅游内容。由此为来到 “秦皇山海、康养 福地” 的秦皇岛居住和旅游的康养群体提供生活和出 游气象服务指导, 为秦皇岛市旅游开发与规划及为研 究气候变化对旅游业的影响提供依据。
致谢

本项目受河北省重点研发计划海洋资源开发利 用与社会事业专项项目 “秦皇岛康养与医疗气象服务 研究”（18275402D）和秦皇岛市气象局重点工作技 术支撑团队项目 “气候舒适度与气象指数研究” （ZD201704）共同资助。

\section{参考文献}

[1] Terjung W H. Physiologic climates of the contentious united states: A Bio-climatic classification Based on man[J]. Annals A A G, 1966, 5(1): 141-179.

[2] Oliver J E. Climate and Man's Environment: An Introduction to Applied Climatology [M]. New York: John Wiley \& Sons Inc, 1973:195-206.

[3] 吴兑,多种人体舒适度预报公式讨论 [J] . 气象科技,2003,31 (6) :370-372.

[4] 郑衡宇,骆培聪,吕刚.福建主要城市周边平缓高地避暑休闲气 候评价[J].亚热带资源与环境学报,2009,4(1):59-70.

[5] 陈桂标. 人体舒适度的预报方法[J].广东气象,2000,4:29-30.

[6] 孙广禄,王晓云,章新平,等.京津冀地区人体舒适度的时空特 征[J].气象与环境学报,2011,27 (3) :18-23.

[7] 肖晶晶, 李正泉, 郭芬芬, 等. 浙江省人居环境气候适宜度概率 分布分析 [J].气象与环境科学,2017,40(1):120-125.

[8] 李树岩,马志红,许蓬蓬,等.河南省人体舒适度气候指数分析 $[\mathrm{J}]$.气象与环境科学,2007,30(4):49-53.

[9] 贾海源, 陆登荣. 甘肃省人体舒适度地域分布特征研究 [J]. 干旱气象，2010,28(4):449-454.

[10] 马丽君, 孙根年, 马彦如, 等.50年来北京旅游气候舒适度 变化分析 $[J]$, 干旱区资源与环境, 2011,25（10）：161-166.

[11] 房小怡, 李磊, 杜吴鹏, 等.近 30 年北京气候舒适度城郊变 化对比分析 $[J]$.气象科技，2015，43（5）:918-924.

[12］金琪,孟英杰.1960-2016 年武汉城市圈人体舒适度变化特征 $[\mathrm{J}]$.气象与环境学报,2017,33（6）:82-88

[13] 李正泉,肖晶晶,马浩,等.丽水市生态气候休闲养生适宜性分 析[J].气象与环境科学,2016,39(3):104-111.

[14] 王秀兰, 卫旭东, 吴亚琪, 等.杭州市近 50 年气候舒适度变 化[J].宝鸡文理学院学报, 2014, 34(3) : 31-35.

[15] 吴世安.信阳市人体舒适度指数变化及未来趋势分析 [J].气 象与环境科学,2017,40(3):59-64.

[16] 张立杰,张丽,李否,等.2011 年深圳人体舒适度空间分布特征 及影响因子分析 $[\mathrm{J}]$.气象与环境学报,2013,29（6）:134-139.

[17] 刘金丽,郑浩阳.珠海市人居环境气候舒适度特征分析 [J].广 
东气象,2016,38（5）:49-53.

[18] 王繁强, 周阿舒,滕丽峰, 等. 日照市人体舒适度指数预报 [J].山 东气象, 2003,23 (2) : 18-20

[19] 赵子健,陈静怡,钟隽文, 等. 基于标准有效温度和不舒适指标 研究南京热舒适状况 [J].气象与环境科学,2013,36(4):16-21.

[20] 李源,袁业畅,陈云生. 武汉市人体舒适度计算方法及其预报 $[J]$.湖北气象, 2000,32（1）:27-28.

[21] 中国天气网北京站. 影响人体舒适度的温度和湿度 [EB/OL].[2016-6-20].http://www.weather.com.cn/Beijing/sygd t/06/2538396.shtml.
[22] 徐静.秦皇岛地区气候资源及农业气候资源特征分析[J].中 国环境管理干部学院学报，2011,21（4）:36-39.

[23] 张楠, 苗春生, 邵海燕.1951-2007 年华北地区夏季气温变化 特征[J].气象与环境学报, 2009,25（6）:23-28.

[24] 唐国利,罗勇,黄建斌,等.气候变暖在继续[J].气候变化研究进 展,2012,8（4）:235-242.

[25] 王海军,张勃,赵传燕,等.中国北方近 57 年气温时空变化特征 [J].地理科学进展,2009,28（4）:643-650. 